\title{
LA SOCIEDAD JAPONESA DE POSGUERRA EN BATALLAS SIN HONOR NI HUMANIDAD: KINJI FUKASAKU Y EL YAKUZA-EIGA
}

\section{JAPANESE POSTWAR SOCIETY IN BATTLES WITHOUT HONOR AND HUMANITY: KINJI FUKASAKU AND THE YAKUZA-EIGA}

\author{
Luis Miguel Machín Martín \\ Universidad de La Laguna, Tenerife
}

\section{Resumen:}

El presente artículo analiza la sociedad japonesa de posguerra a través del yakuzaeiga de Kinji Fukasaku. En concreto, este artículo se centra en la saga Batallas sin honor ni humanidad, que narra la ascensión de un ex soldado en una familia mafiosa de la ciudad de Kure. La saga se inicia al finalizar la Segunda Guerra Mundial, haciendo avanzar sus tramas hasta inicios de la década de los 70 . Batallas sin honor ni humanidad es la visión de un director que vivió la posguerra y que pudo observar cómo la sociedad japonesa se transformó desde el fin de la guerra, en 1945, hasta el presente. Para explicar su postura, Fukasaku centra la saga en la lucha que se produce en los bajos fondos de la Prefectura de Hiroshima, donde varias familias de la yakuza peleaban por el territorio. A través de esa batalla criminal, Kinji Fukasaku expone los avances y contradicciones de un país en reconstrucción.

\section{Palabras clave:}

Fukasaku; cine; yakuza-eiga; posguerra

\section{Keywords:}

Fukasaku; cine; yakuza-eiga; postwar

\begin{abstract}
:
This paper analyzes the Japanese postwar society through Kinji Fukasaku's yakuzaeiga. Specifically, this paper focuses on Battles Without Honor and Humanity saga, which relates the ascension of an ex soldier in a yakuza family from Kure. Without Honor and Humanity begins at the end of the Second World War, continuing with the plot until the first days of the '70. Battles Without Honor and Humanity resume the vision of a director that lived the postwar period and could notice how the Japanese society has changed since the end of the war in 1945 until the current moment. To explain his personal view, Fukasaku focuses the saga on the struggles made by the population living against the background in the Prefecture of Hiroshima, where many families of the yakuza fought with each other for the territory. Through this criminal battle, Kinji Fukasaku presents the progresses and contradictions of a country in rebuild.
\end{abstract}




\section{Estado de la cuestión y metodología}

\subsection{Estado de la cuestión: breve aproximación a la consideración actual como cineasta de Kinji Fukasaku}

Con una trayectoria cinematográfica dispar, Kinji Fukasaku (1930 - 2003) supo adaptarse a cada nueva coyuntura haciendo remarcables obras en cada década de actividad. Comenzó en los años 60 alternando cine criminal con obras de difícil clasificación como El lagarto negro (Kuro tokage, 1968) o Batalla más allá de las estrellas (The Green Slime, 1968). Aunque, observando desde la distancia, esa alternancia entre producciones de género y otras obras heterogéneas del inicio de su carrera acabó siendo una constante a lo largo de su filmografía.

Su huella en el cine criminal -el yakuza-eiga principalmente- iba a ser de forma previsible su más remarcable aportación al cine japonés, sin embargo en el año 2000 estrena una de esas raras obras que plagan su filmografía: Battle Royale (Batoru Rowaiaru). Distópica, arriesgada, violenta (no más que el resto de su cine) e icónica, Battle Royale acabaría siendo su mejor carta de presentación, una película que se fue directa a los altares del culto de los aficionados al cine japonés. $\mathrm{Y}$ desde entonces, pocas -al menos no las suficientes- son las referencias a Fukasaku que se centran en el cineasta potente y de género que explotó en los 6os y 70 .

En una reseña del libro Kinji Fukasaku: Un cinéaste critique dans le chaos du xxe siècle, escrito por Olivier Hadouchi (2009), el crítico y productor Hubert Niogret señala un rasgo que el propio Fukasaku destacaba:

Fukasaku nunca se consideró como un autor sino como un fabricante de películas de género, trabajando por encargo para las majors japonesas (...) su enfoque no deja de ser personal (a diferencia de sus colegas [cineastas] que trabajaban en el mismo género), a veces iconoclasta, a menudo frontalmente crítico con la sociedad y la época a la que pertenece, (Niogret, 2011, p. 66).

En cuanto a la saga Battles Without Honor and Humanity, es reseñable la poca cantidad de ediciones que se ha realizado de dicha obra, habiendo localizado el 
autor de este artículo solamente una edición alemana y otra estadounidense. Esto puede expresar el poco reconocimiento que el director japonés ha recibido por parte de aficionados -a excepción de los fans de Battle Royale- y por parte de la crítica occidental -de nuevo, a excepción de ciertos especialistas-. Aunque, tal vez, sea un error hablar de poco reconocimiento en vez de desatención, pues la poca literatura disponible acerca de Kinji Fukasaku desmerece sus logros cinematográficos principalmente en lo que se refiere a la renovación del cine japonés en los años 70.

A ese respecto, el director William Friedkin, en unas declaraciones incluidas en una edición de 2004 (Home Vision Entertainment) de Battles Without Honor and Humanity, comentó que frente al estilo del cine japonés clásico que abanderaban Ozu, Kurosawa u Oshima, el cine de Fukasaku rompía con esa tradición aproximándose al cine americano de los 70. Según él, "en el universo Fukasaku los personajes no necesitan ser reconducidos", pues todo el mundo comete errores y, como en la vida real, no siempre es posible un buen final. Añade, además, que "las películas que se hacen hoy en Hollywood son muy predecibles", y que, sin embargo, Battles Without Honor and Humanity se trata de una serie de películas totalmente impredecibles y que eso las convierte en un gran entretenimiento para el espectador.

Refiriéndose a Fukasaku en términos de maestro (master), Friedkin culmina su comentario haciendo referencia a la forma de reflejar su tiempo que tenía el director nipón, definiendo de paso una de las características que a su juicio tienen los grandes cineastas: "los grandes cineastas, y Fukasaku lo era, reflejaban su tiempo en su cine y además ejercían de profetas acerca de lo que ocurriría a continuación en la historia”. Aplicado a Battles Without Honor and Humanity, queda claro que la válida opinión del notable director William Friedkin es la de que Fukasaku fue un realizador con una visión clara de su entorno, capaz de prever la evolución de su sociedad y plasmarlo, de paso, en sus películas. 


\subsection{Objetivos y metodología}

El objetivo de este texto es analizar cómo la saga Battles Without Honor and Humanity presentó al Japón post Segunda Guerra Mundial, y reflejar cómo su director, Kinji Fukasaku, plasmó sus experiencias e ideas sobre el nuevo Japón que se puso en construcción inmediatamente después del fin de la guerra. Aunque Battles Without Honor and Humanity no se limitó a retratar la posguerra, sino que, aplicando la distancia temporal (desde el fin de la II Guerra Mundial hasta el estreno de la primera película de la saga pasaron 28 años) presentó al nuevo Japón, erigido a partir del trauma de la guerra, presentando también, indirectamente, las ganas de separar la anterior etapa belicista de la nueva etapa de paz por parte de la población japonesa (Shimazu, 2003, p. 101). De forma colateral, y aprovechando el análisis de la saga citada, el artículo examina algunas de las aportaciones del cineasta al género yakuza-eiga.

La metodología empleada siguió las fases iniciales del modelo propuesto por Gómez Tarín (2010, pp. 68-76): primero, se siguió la llamada Fase previa, con el fin de contextualizar histórica, económica, social y cinematográficamente, el cine de Kinji Fukasaku, principalmente la saga Battles Without Honor and Humanity. Dicha fase de documentación puso su foco en el Japón de posguerra, con el fin de comprender mejor al estado japonés antes y después de la guerra. Todo ello, por supuesto, sin olvidar la lectura de literatura sobre las circunstancias del nacimiento de la saga, así como de las características del cine de Fukasaku y del género de la saga.

Durante un segundo paso metodológico, el análisis se centró más en la observación de los hechos narrados que en su forma, tomando para ello algunas propuestas de análisis temático realizadas por Aumont y Marie (1988, pp. 130133). Dicho de otro modo, sin desechar el análisis formal de las obras de Fukasaku, se puso más la atención en el relato que en el contenedor de dicho relato. 
De esta forma, este artículo trata de relacionar los hechos históricos que siguieron al fin de la II Guerra Mundial en Japón a través del desarrollo y expansión que experimentaron las familias mafiosas durante décadas.

\section{Contexto histórico y cinematográfico}

La posguerra como coyuntura social y económica ha sido retratada en varias ocasiones en la historia del cine. Este cine, lejos de dar tiempo a cicatrizar las heridas de la guerra, narra la situación del país en cuestión al mismo tiempo que éste sufre los achaques de una economía deprimida y de una sociedad desestructurada. Esta contemporaneidad del cine y el sufrimiento de su país sugieren un alto grado de compromiso por parte de los cineastas. Compromiso con unos ciudadanos perdidos, compromiso que permite servir de documento visual para el futuro, y de crítica para el presente. Han sido muchos los movimientos cinematográficos que han basado su contenido en la coyuntura de su país - casi siempre en tiempos de crisis- pero unos pocos han sido los que han trascendido, convirtiéndose en iconos.

El caso más conocido de esta crítica contemporánea a los sucesos acaecidos en una situación de guerra y posguerra es el del neorrealismo italiano, tal vez por haber sido el primer movimiento con características claras y definidas en nacer:

El neorrealismo cambia la visión del séptimo arte como mera forma de distracción para, haciendo honor a su nombre, convertirse en una herramienta de polémica y crítica social a la situación de posguerra que sufrió Italia durante y sobre todo tras la Segunda Guerra Mundial, (Caldevilla, 2009, p. 2).

De este modo, el cine de posguerra surge como un llamamiento a la conciencia. El cine deja de ser únicamente objeto de diversión y pasa a ser un importante órgano de denuncia. Por supuesto, existen más casos, casos más cercanos geográficamente al objeto de este estudio: el neorrealismo japonés.

El caso del neorrealismo japonés es especial. El Estado nipón firma su rendición en la Segunda Guerra Mundial el 2 de septiembre de 1945, y acto seguido la nación sufre un proceso de ocupación por parte del bando aliado. Lo especial de este caso es que esta ocupación no sólo empleó su poder para impedir un 
rearme militar sino que aprovechó la situación para establecer un control ideológico sobre todo producto y obra creada. Las tropas estadounidenses destinadas a la ocupación japonesa se encargaron del control directo de los medios de comunicación y de la industria cinematográfica, teniendo por objetivo eliminar cualquier vestigio militarista o medieval de las producciones nacionales. En ese proceso, quedó patente un sentimiento de devastación en ciertas obras que algunos autores han venido a llamar Neorrealismo japonés (Giménez, 2008, pp. 2-3).

Akira Kurosawa fue el máximo exponente de este Neorrealismo japonés con obras como El ángel ebrio (Yoidore tenshi, 1948) y El perro rabioso (Nora inu, 1949), además de Los hombres que caminan sobre la cola del tigre (Tora no o wo fumu otokotachi, 1945), primera película en la que Kurosawa tuvo contacto con la censura de la ocupación aliada, si bien este caso fue el de una censura amistosa (Smith, 2013, p. 65). El ángel ebrio y El perro rabioso combinaban ese componente crítico con un cine negro clásico adaptado a las circunstancias japonesas. El cine neorrealista de Kurosawa recogía -la censura de la hacía imposible otra cosa- ciertos elementos arraigados de la guerra. A saber, un sentimiento de humillación derivado de la gran cantidad de bajas militares y civiles que había provocado la guerra -alrededor de un millón y medio de bajas militares (Coox, 1988, pp. 366-7), y 400.00o bajas civiles provocadas por los bombardeos (Bailey, 1996, p. 22) -. Además, hay un dato bastante gráfico que habla de las condiciones que sufría la población japonesa: en 1944 Japón había sufrido una reducción del $17 \%$ de las calorías diarias consumidas por los civiles desde 1941. En cambio, la reducción que sufrieron los civiles británicos fue de un $2 \%$, mientras que Alemania aumentaba su dato en un $1 \%$ y los civiles estadounidenses veían reducida su dieta calórica en un 4 \% (Havens, 1978, p. 130). No es de extrañar, por tanto, ese sentimiento de rabia e impotencia presente en estos filmes neorrealistas.

En cuanto a la mencionada censura, hay que hacer referencia al SCAP, siglas en inglés del Comandante Supremo de las Fuerzas Aliadas, figura representada por el General Douglas MacArthur durante casi toda la ocupación de Japón. Inicialmente, SCAP eran las siglas referidas a dicho puesto, sin embargo acabó 
siendo también el acrónimo para aludir a todas las oficinas, organismos, personal y, en fin, a toda la estructura que el bando aliado había constituido en Japón en la posguerra para su control y progresiva implantación de un régimen democrático sin vestigios imperialistas.

De entre las muchas funciones que tuvo el SCAP en el Japón de posguerra, la censura y el control de las comunicaciones fue una de las más importantes. Se sometía a escrutinio cada medio impreso, cada guión, cada película antes de su estreno o publicación (Rubin, 1985, p. 84). No sólo eso, el SCAP llevó a cabo una reestructuración de la industria cinematográfica, favoreciendo la producción de películas optimistas con el futuro de Japón, que promocionaran un estado moderno alejado del país de preguerra (Shimazu, 2003, p. 103).

A pesar de todo, la ocupación aliada no fue vista con malos ojos por una buena cantidad de japoneses. Otra de las funciones del SCAP fue acabar con el Estado Shinto, reflejo del Japón de viejo cuño, imperialista y militarista. El Estado Shinto protagonista de numerosos estudios, es un régimen difícil de definir, cuyo concepto básico puede ser alterado por pequeños matices (Shimazono, 2005, p. 1079). Lo primero que hay que exponer es que el término shinto alude a una religión japonesa, cuyas creencias se basan en los kami, espíritus con la categoría de deidades. Pero... ¿̇qué implicaciones tuvo dicha religión con el estado japonés? ¿Hasta qué punto el sintoísmo se apoderó del Estado? Un posible acercamiento a la definición del periodo del Estado Shinto (1868-1945) es el siguiente: "durante décadas, los elementos sintoístas obtuvieron influencia y control manifiesto sobre el Estado, al tiempo que el gobierno japonés utilizaba el culto a los santuarios como una fuerza mayor para movilizar la lealtad imperial del pueblo, en nombre de la construcción de una nación moderna”, (Fridell, 1975, pp. 547-561). Sin embargo, a dicha definición le falta un elemento importante, y ése es la personalización del Estado Shinto en el mismo emperador japonés, que representaba la simbología y rituales sintoístas, convirtiendo a estado y religión en algo inseparable (Masafumi, 2010, p. 398).

No obstante, lo que produjo, en última instancia, el rechazo del pueblo japonés hacia el régimen fue su imperialismo, que había traído la guerra a Japón durante décadas de invasiones y conflictos militares, bajo el paraguas del culto 
sintoísta (Fukase-Indegaard \& Indegaard, 2008, pp. 343-374). Desde esta lectura, fue el Estado Shinto el que produjo la devastación de la II Guerra Mundial de forma indirecta, y no extraña, por tanto, la indirecta simpatía con que parte de la población japonesa tomó la invasión aliada. De hecho, dados los precedentes de censura, el mencionado Akira Kurosawa se convirtió en una voz autorizada para hablar del tema. En una entrevista, a la pregunta "¿Se sintió aliviado y experimentó alegría con la derrota de Japón?”, Kurosawa respondió con un rotundo "Sí". Además, en la misma entrevista, el director afirmó: "En muchos asuntos, el GHQ [General Headquarters, siglas que aluden al SCAP] hizo un gran esfuerzo por reconstruir Japón”, (Kurosawa, 2013, pp. 64-65). Queda así registrado el sentimiento de algunos japoneses, aliviados por la derrota y el fin de la guerra, felices por estar en manos del órgano del SCAP, pese a la censura y al control estatal. Nunca antes hubo una relación tan satisfactoria entre una potencia militar que ocupa la nación de otra potencia, como en el caso de Japón y Estados Unidos; ambos países comparten el crédito del provechoso desarrollo del estado asiático (Lagos Matus, 2011, pp. 255-274).

De esta manera se comprenden mejor los antecedentes del Japón previo al que Fukasaku plasmó en su saga, un Japón con el que los japoneses ya no se identificaban, un Japón a olvidar. Empezó así una huida hacia delante del país, de la cual el director fue testigo privilegiado.

Kinji Fukasaku comenzó su producción en la década de 1960, bajo el sello Toei. Con esta compañía, Fukasaku realizó películas de diversos géneros hasta que demostró tener habilidad cinematográfica y comercial en el yakuza-eiga. Eso le llevó a explotar el género en numerosas películas. Las más destacadas fueron las agrupadas en la saga Battles Without Honor and Humanity (Jingi naki tatakai) [también conocida como The Yakuza Papers], que narraba la ascensión en una familia mafiosa de un ex soldado del ejército japonés desde el fin de la II Guerra Mundial hasta los años 70. La saga se rodó entre 1973 y 1974, lo que la distancia enormemente de los filmes de posguerra anteriormente citados.

Ésa es la principal diferencia entre las obras neorrealistas de Kurosawa y Battles Without Honor and Humanity: las primeras se limitaban a documentar y criticar la situación en el país durante la ocupación de las tropas aliadas. Sin 
embargo, las películas de Fukasaku están realizadas desde la distancia que da el tiempo, desde una perspectiva totalmente diferente: transcurridas dos décadas, la posguerra japonesa podía analizarse de forma fría, deteniéndose a establecer diagnósticos coyunturales. $\mathrm{Y}$ eso es lo que hizo Fukasaku, tomar el espacio temporal y su experiencia vital para retratar la crisis de posguerra que Japón vivió, y estudiar cómo desde los escombros de una nación destruida emerge otra nación completamente nueva.

\section{La juventud perdida: la yakuza como desarrollo personal}

\subsection{Los jóvenes y la yakuza}

El siglo XX trajo consigo un aumento de la eficacia militar heredada del desarrollo tecnológico propio de la revolución industrial. Esta eficacia potenciada unida a aumento de la población mundial y de la aglomeración demográfica en grandes ciudades, propició algo que, hasta entonces, se había dado en contadas ocasiones en la historia: vacíos demográficos, generaciones enteras muertas, perdidas y paralizadas social y económicamente. Fue lo que autores como John Dos Passos, Ernest Hemingway o William Faulkner acabaron abanderando y titulando como Generación Perdida, la generación perdida de la Primera Guerra Mundial.

También es célebre el caso de la Generación Beat y la Segunda Guerra Mundial. Los beats eran jóvenes estadounidenses que habían sufrido los horrores de la guerra de forma directa o indirecta. Habían entrado en contacto con la proximidad de la muerte $\mathrm{y}$, por tanto, sus actos tenían un halo de despreocupación y de tristeza. El país norteamericano había cambiado mucho desde el inicio de la guerra hasta su fin. El mundo entero había cambiado. La posibilidad de una muerte inminente e instantánea, fruto de la concienciación acerca de la bomba atómica con la guerra fría de fondo (Maffi, 1975, p. 14), les había atenazado, hasta convertirlos en una generación ambulante.

Los estandartes de esta Generación Beat fueron, como en el caso de la Generación Perdida, escritores. Nombres ahora conocidos como Jack Kerouac o Allen Ginsberg fueron las cabezas visibles de esa generación, pero de ningún 
modo fueron los únicos pertenecientes a ella. En general, los mismos escritores fueron quienes se encargaron de delimitar esta corriente. Su principal ideólogo fue John Clellon Holmes, alguien cercano al movimiento en sus inicios, luego más distanciado. John Clellon Holmes puso tierra de por medio, de modo que pudo hacer un análisis menos calculado y pasional, y probablemente más cercano a la realidad de lo que podían hacer los escritores inmersos en la movida. Holmes, en su famoso artículo-manifiesto titulado This is the Beat Generation, afirmó:

Sus miembros poseen una instintiva individualidad que no precisa de la bohemia ni de excentricidades impuestas para expresarlas. Nacidos durante las desastrosas condiciones sociales de una profunda depresión económica, criados durante el desarraigo masivo de una guerra mundial, desconfían totalmente de la colectividad. (...) La paz que heredaron era tan definitiva como lo que podía durar el siguiente titular de los periódicos. Era una paz fría, (Holmes, 1997, pp. 39-41).

Esta descripción de los miembros de la Generación Beat tiene muchos paralelismos con los sentimientos de los jóvenes supervivientes de la Segunda Guerra Mundial en Japón. Con el país destruido a nivel de infraestructuras, desmoralizado y humillado por la derrota, la juventud se sintió desamparada. Tal y como el mismo Kinji Fukasaku relató en una entrevista: "durante la guerra nos enseñaban a luchar hasta el fin y morir (...) Nuestros padres no nos decían que teníamos que morir, pero tampoco decían lo contrario", (Schilling, 2007, p. 154). Toda esa retórica militar y épica llevada a cabo por el régimen imperial japonés se hundió rápidamente tras la ocupación de los aliados, y los jóvenes se encontraban con un vacío moral y familiar, vacío que podía ocupar la yakuza, con su dinero fácil, su código moral con el supuesto referente del código samurái, y con sus cortas metas vitales.

Ese hueco no fue ocupado ni siquiera por la ética familiar. De hecho, la pérdida de todo recurso económico y material convertía a los padres en progenitores sin poder moral sobre sus hijos. En una época donde los adultos enseñaban a los jóvenes a morir, pero no a vivir la mafia ofrecía un estilo de vida, un sueldo, algo a lo que la propia nación no podía responder de forma inmediata (Schilling, 2007, p. 154). Sin embargo, es erróneo establecer una confrontación entre el Estado y las organizaciones criminales dada su relación en la posguerra, cuando 
la derecha política se apoyó económicamente en los grupos mafiosos, entre otras instituciones y empresas (Tsujikawa, 2007, p. 27).

\subsection{Los marginados y la yakuza: los orígenes}

Uno de los posibles orígenes remotos de los yakuza está en el inicio de la Era Tokugawa (también conocida como Periodo Edo, 1603-1868). En 1603, comienza el shogunato Tokugawa, que había unificado gran parte del territorio japonés, si bien seguía habiendo zonas sin clara delimitación política según los estándares occidentales (Howell, 1998, p. 105). Con la unificación, se llegó a una relativa situación de paz en la que los ejércitos, compuestos por guerreros samurái, se volvieron poco útiles. Alrededor de 500.000 samurái quedaron sin empleo; algunos empezaron a servir a mercaderes, otros, en cambio, se dieron al saqueo y bandidaje (Dubro \& Kaplan, 2007, p. 53).

La yakuza históricamente se ha asociado a sí misma a respetables grupos de la Era Tokugawa, tales como los machi-yakko (servidores de la ciudad), enemigos de los hatamoto-yakko (servidores del shogun), (Fisher, 2012, p. 1). Aunque lo más probable es que no procedieran de ninguno de esos dos grupos. Tal y como afirma Fisher (2012, p. 3): "las primeras bandas consideradas originarias de la yakuza fueron organizaciones ilegales que aparecieron entre los siglos XVII y XVIII, durante el Periodo Edo. Esas bandas se dividieron entre los bakuto (jugadores, tahúres) y los tekiya (buhoneros)”.

Los bakuto pronto se convirtieron en una banda violenta, formada por pequeños artesanos, campesinos y samuráis. El término yakuza acabó acuñándose gracias a los bakuto, que se lo llamaban a sí mismos, por su gran afición al juego, y es que el término proviene del juego de cartas hanafuda, cuya combinación perdedora en japonés es ya-ku-sa. En cuanto a los tekiya, puede hacerse referencia a su tradicional forma de hacer negocios: las estafas (Dubro \& Kaplan, 2007, p. 58). Aunque en sus inicios, los bakuto y los tekiya compartían la asimilación en sus grupos de diferentes personas inadaptadas, los tekiya comenzaron a aceptar y atraer a los marginados de la sociedad japonesa: los burakumin. 
Los burakumin eran los descendientes de los eta, el estrato social más bajo de la Era Tokugawa, también conocidos como eta-hinin (Shimahara, 1984, p. 340). Los burakumin, parias de Japón, eran obligados por ley a ejercer las profesiones consideradas indignas, como las relacionadas con los cadáveres o con la carnicería (Hah \& Lapp, 1978, p. 488). Y es que desde la Era Tokugawa, se tenían registros en los que figuraban los parias, luego sustituido por otro sistema de registro familiar en el Periodo Meiji (Winther, 2008, p. 23). Con dichos registros, los marginados apenas tenían oportunidad de escapar de su estatus social, condenados a la exclusión, condenados sus hijos también al destierro comunitario por herencia de sangre. $\mathrm{Y}$ aunque ese sistema de castas tan dado a la discriminación fue eliminado y transformado en el de la mencionada Restauración Meiji, sus ecos llegan hasta la actualidad, donde sigue habiendo una gran cantidad de descastados o burakumin. Tanto es así, que en el siglo XX se han creado diferentes asociaciones cuyo objetivo es la defensa de los burakumin, como el Movimiento de Liberación de la Comunidad Buraku (Guerrero, 2009, p. 222).

Volviendo a los tekiya, se entiende la relación de simbiosis entre los miembros de la banda y estos parias, ya que ambos, de algún modo, vivían al margen de la ley. Los tekiya perdían el poco estatus social que podían tener cometiendo delitos, lo que les convertía en iguales a los eta o burakumin (Dubro \& Kaplan, 2007, p. 60). Y es esa la relación que se podría establecer en la yakuza representada por Fukasaku en Battles Without Honor and Humanity y los marginados, olvidados, huérfanos y jóvenes sin futuro, una relación marcada por la inicial igualdad de estatus entre unos y otros.

\section{Kinji Fukasaku: breve retrato filmográfico}

Nacido en julio de 1930 en Mito, en la región de Kanto, lugar tradicionalmente propicio para la formación de yakuzas (Schilling, 2007, p. 156). Ese 1930 precedió a la invasión de China por parte de Japón. Más tarde, Kinji Fukasaku viviría de lleno la Segunda Guerra Mundial, así que puede entenderse su cruda visión de la realidad plasmada en su filmografía, donde no hay concesiones: la 
violencia existe, es real, e incluso necesaria en el cine. En la entrevista citada en este artículo, Fukasaku hace una declaración de principios:

La violencia es uno de los elementos básicos del cine: es lo que podría denominarse la columna vertebral del cine. Otro es el elemento "información": la información social que transmiten las películas. Un tercero es la moda. Son tres pilares del cine, no sólo en Japón, sino en todas partes, con el sexo como parte integrante de la moda. De los tres, el que más rápido llega al público es (cuando yo empecé) la violencia. El motivo era que Japón había perdido la guerra. Antes de la guerra y en el tiempo que duró había dos grandes pilares. El primero era la violencia, algo esencial en los dramas de época, el género más importante de la industria japonesa. El segundo era lo romántico, un elemento de gran relevancia en ambos periodos y en las películas contemporáneas (p. 156).

La violencia es, por tanto, uno de los pilares del cine, y el director nipón llevó esa máxima hasta las últimas consecuencias. Es por eso que su estilo es considerado excesivo continuamente por algunos críticos, si bien esos excesos se encuadraban dentro de una cinematografía y género dados al desbordamiento violento y casi surrealista, como los llevados a cabo por un director bastante afín a Fukasaku, Seijun Suzuki, quien profundizó en el thriller utilizando a la yakuza para ironizar sobre ella, llegando casi al punto de la parodia (Aguilar, 2001, p. 4), lo que se distanciaba ligeramente del cine de Fukasaku.

Aunque, como apunte, hay que recordar que Kinji Fukasaku no era militarista ni hacía apología de las armas. De hecho, en 1972 dirigió una de sus obras capitales, Bajo la bandera del sol naciente (Gunki hatameku motoni), película que criticaba la guerra y su acción en el corazón de los hombres -convertidos en mentirosos, cínicos, salvajes-, así como al Estado japonés tras la guerra, que obstaculizaba la verdad a través de la burocracia.

En la década de los 50, las productoras habían ampliado su inversión en el cine de acción y thrillers, amparándose en el estricto control que la SCAP había ejercido para impedir que se continuaran realizando películas de época (jidaigeki), que recordaban de alguna forma a la etapa militarista e imperialista japonesa (Aguilar, 2001, p. 3). Así pues, podría considerarse que ese cine de acción fue algo así como la respuesta al cine de preguerra, renegando de la tradición, pero bebiendo al mismo tiempo de ella, pues la yakuza, tal y como se ha expuesto, se reflejaban, al menos parcialmente, en esos samuráis retratados 
en el jidai-geki. Se establece, por tanto, una interesante retroalimentación genérica e identitaria entre ambos cines.

Por tanto, el yakuza-eiga (cine de yakuzas) no fue fruto de una gran tradición ni mucho menos. Fue, respetando las diferencias, una rápida adaptación del cine de Hollywood a Japón (Schilling, 2007, p. 72), sin unos límites marcados, sin moldes. Fue una creación espontánea, que luego sí tendría dos momentos bien diferenciados.

Iniciada su carrera a principios de los años 6o, la productora Toei fue la casa de Kinji Fukasaku durante la mayor parte de su filmografía. Toei había explotado la primera etapa del yakuza-eiga, el ninkyo-eiga, a lo largo de esa década de 1960, hasta agotarlo. Ese ninkyo-eiga se caracterizaba por unos personajes de moral tradicional, con una violencia poco visceral, más en concordancia con la corriente cinematográfica mundial. Sin embargo, Fukasaku era portador de otro estilo, más potente, más arrogante, estilo que no gustaba a los directivos de Toei. Dicho estilo, más cercano a la modernidad cinematográfica, acabó convenciendo a los hombres trajeados de la productora tras rodar Street Mobster (Gendai yakuza: hito-kiri yota, Kinji Fukasaku, 1972). Así, Fukasaku tuvo luz verde para iniciar la saga de Battles Without Honor and Humanity, que abanderaba la segunda etapa del yakuza-eiga, el llamado jitsoroku-eiga, con un estilo más vigoroso, menos grave, cercano en muchas ocasiones al cinéma vérité. Un género exhausto como el de la mafia japonesa tuvo una segunda vida gracias al nuevo enfoque de sus tradicionales tramas, como el espagueti western extendió los límites del western original.

Analizando fríamente el conjunto de la filmografía de Fukasaku, podría llegarse a la conclusión de que su papel en el cine japonés fue similar al de Don Siegel O Peckinpah en Estados Unidos: el papel de transición entre el clasicismo agonizante y la modernidad. Un papel en ocasiones desdeñado pero necesario. Porque estos cineastas recrudecieron su cine hasta límites desagradables en su momento, que les convertía en realizadores imprevisibles y aparentemente caóticos, pero sin los cuales no se puede entender bien la década de los 70 en la cinematografía de los dos países. 


\section{La sociedad japonesa de posguerra a través de Battles Without}

\section{Honor and Humanity}

Battles Without Honor and Humanity no solo contaba cómo un ex soldado japonés se introducía en el mundo de la mafia en el Japón de posguerra, sino que, en conjunto, contaba la evolución de un país, el desconcierto del caos. [La saga, por cierto, se basó en una serie de artículos de revista publicados en la época sobre Kozo Mino, un antiguo jefe de la yakuza (Schilling, 2007, p. 82), de ahí el sobrenombre de The Yakuza Papers]. Tal y como el narrador relata al inicio de la primera entrega de Battles... "Un año después de la rendición de Japón, la violencia de la guerra ha acabado. Pero un nuevo tipo de violencia la ha reemplazado en un Japón sin leyes. Cada hombre vela por sus intereses en medio del caos". Nos encontramos, pues, ante una sociedad egoísta, principalmente en los salvajes y desordenados mercados de las ciudades. Los individuos justifican la violencia y el egoísmo basándose en su propio bienestar. No es, por tanto, una exaltación de la libertad individual, no hay nada de político en esta actitud: es el resultado de una población que quiere sobrevivir.

Esa evolución de un país caótico en una sociedad moderna y estructurada también puede observarse desde el mismo título original de la saga: Jingi naki tatakai. En el título, jingi hace referencia al Sanshu no jingi, expresión que alude a los tres Tesoros Sagrados de Japón. A saber: una espada, unas joyas y un espejo. Pero a mediados de los años 50, empezó a aparecer una nueva interpretación de la expresión, que esta vez hacía referencia a una lavadora, un frigorífico y una televisión en blanco y negro (Yoshimi, 2005, p. 546), símbolos de la nueva sociedad japonesa.

Las primeras escenas de esta primera entrega lo evidencian: la violencia se sucede. Primero, un intento de violación a una japonesa por parte de unos soldados de la ocupación aliada -violación, por cierto, evitada por el protagonista de la saga-. Luego, un enfrentamiento entre mafias que se salda con un brazo amputado a espada. Y todo en la misma localización: un mercado. Un mercado que es como el paradigma de ese caos, el escenario de la ebullición 
de la sociedad japonesa de posguerra. Un mercado que podría estar localizado en cualquier ciudad nipona, pero que Fukasaku, con mucha inteligencia, sitúa en Kure, ciudad de la Prefectura de Hiroshima, lo que le permite acercarse al drama del bombardeo atómico, manteniendo una estratégica distancia donde desarrolla las tramas con la guerra como telón de fondo.

Ese ex soldado mencionado con anterioridad es Shozo Hirono, uno de tantos militares recién llegados de la guerra, militares ahora sin rumbo. Ésa es otra de las novedades que impuso Fukasaku: el protagonista no es el único vagabundo hambriento y en busca de trabajo, sólo es uno más entre miles de militares y civiles sin hogar (Phillips, 2009, p. 35). De fuerte carácter, fácilmente irascible, Hirono buscará venganza en el mercado por las heridas producidas a uno de sus compañeros excombatientes. El agresor -que hirió al amigo del protagonista con una espada- se enfrenta a Hirono cuando éste viene a reparar el daño producido. Hirono previamente había obtenido una pistola de unos yakuza próximos a su compañero soldado herido. El resultado, previsible: Hirono asesina al agresor y acaba en prisión.

Es curioso, por cierto, cómo poco después de evitar una salvaje violación en el mercado, Hirono entre en la cárcel por un delito de naturaleza tan diferente: no hay culpables ni inocentes en el Japón de posguerra, quien se comporta heroicamente en un momento, puede ser el mayor canalla acto seguido.

Pronto aparece otro escenario representativo: una cárcel. Una cárcel rebosante. Las cárceles de posguerra, según la visión del filme, albergaban, entre otros delincuentes, a miembros de la yakuza. E Hirono, como no podía ser de otra forma, vuelve a entrometerse en una trifulca carcelaria, cuyo resultado se salda con un internamiento en una celda de aislamiento junto con otro preso participante en la pelea. Pronto descubre Hirono que su nuevo compañero de celda era un capitán de la familia Doi. Éste le pide ayuda a Hirono para realizar correctamente el hara-kiri, quien se presta a ayudarle, avisándole previamente de que no forma parte de la yakuza. El miembro de la familia Doi responde: "Nadie nace yakuza". Establece así un vínculo con Hirono, que tras salir de prisión es aceptado en la familia del fallecido por su honorable asistencia en la ceremonia suicida. De esto se deducen dos cosas: por un lado, que el ser yakuza 
no es una opción temporal, se pertenece a la familia en cualquier circunstancia, en cualquier momento; por otro lado, también se deduce que en la yakuza cinematográfica de Fukasaku los vínculos mafiosos en Japón no se basan en la pureza de la sangre, sino en el prestigio que un hombre genera sobre sí mismo a través de sus actos.

La mafia surge como las raíces de un enorme eucalipto, extendiéndose hacia todos los estratos sociales: desde las abandonadas calles, pasando por las cárceles, hasta los núcleos de poder, entre empresarios y políticos, tal y como Battles... lo muestra. Una secuencia narra cómo un político ofrece vías a la legalización de la familia Yamamori - a la que pasa a pertenecer Hirono tras ser excarcelado-, a cambio del asesinato y extorsión en la región para asegurarse su victoria en las elecciones. El país fue gobernado desde la ocupación aliada hasta el final del siglo XX por el partido liberal-democrático, que se sirvió de sus relaciones con la mafia para expandir su poder (Armao, 2003, p. 32).

En la segunda parte de la saga, titulada Deadly Fight in Hiroshima, Fukasaku muestra cómo los jefes manipulan a sus secuaces de forma cínica, lo cual es una evolución en cuanto al ninkyo-eiga (Riis, 2006, p. 3), donde las decisiones de los jefes tienen un trasfondo de solemnidad, de verdad, de sentido de deber deber en el aspecto que Ruth Benedict resaltó en su célebre obra El crisantemo y la espalda, como algunas de las virtudes apreciadas en la cultura Japonesa: conocer el lugar propio en la sociedad y en una institución, conservar la reputación, etc.-. Ése es el cambio entre las dos fases del yakuza-eiga, un cambio también producido en la misma sociedad, puesto que se paulatinamente se iba produciendo un acercamiento entre la cultura tradicional japonesa y la cultura occidental, mucho más descreída, mucho más alejada de las costumbres que Japón había conservado durante siglos por su aislamiento cultural y económico.

Esa evolución social venía, también, determinada por una mejora en la economía. No era la primera vez que Japón demostraba su fortaleza en este aspecto. El mejor ejemplo se dio pocos años antes, cuando tras el Crack del 29, Japón fue el primer país en salir de la crisis (Rodao, 1995, p. 71). En el caso de la Segunda Guerra Mundial, la semilla de la recuperación económica fue esa 
idiosincrasia japonesa: seguir rindiendo, seguir adelante con lo que un occidental interpretaría como estoicismo, ser útil al colectivo mientras las cosas mejoran. Tal y como afirma Daniel Rubio:

Durante la ocupación la industria siguió su curso, y su bonanza se puede explicar hoy más por el modo de actuar de acuerdo a las ideas confucianas que por un giro en las lealtades del pueblo. Sin embargo, algo ocurrió en la política (...) Para alcanzar el éxito, Japón siempre ha antepuesto a la comunidad por encima del individuo. Todos los japoneses se entregarían a la lucha por la restauración de la prosperidad, y para ello la armonía propia del confucianismo seguía siendo elemental, (Rubio, 2005, p. 259).

A partir de la mitad de la década de los 50, empieza a consumarse el "milagro japonés”, que combina el aumento de la producción -precedida de la reforma agraria - con un acercamiento al ideal de estado de bienestar (Falck, 2007, p. 174). Es entonces cuando la yakuza empieza a asentarse, según la saga de Fukasaku. Su tercera parte, titulada Jingi naki tatakai: Dairi senso (The Yakuza Papers Vol. 3: Proxy War, 1973), comienza en 1960, donde las diferentes familias con base en la prefectura de Hiroshima comienzan a luchar entre sí por el terreno. Ya no basta con crecer, el siguiente objetivo es aplastar a las bandas rivales. La violencia sigue en primer plano, fruto de un Estado aún desestructurado y aliado con la mafia.

En Proxy War, en cuanto a nivel social y económico, Fukasaku muestra ciertos detalles que hablan del retraso que el director percibía una década antes de rodar la película, en 1961. Un ejemplo de ello es la escena en que uno de los matones de la recién formada familia Hirono visita a su madre y le ofrece cigarros norteamericanos, a lo que su madre responde aceptando el ofrecimiento con una gran sonrisa.

En Jingi naki tatakai: Chojo sakusen (The Yakuza Papers, Vol. 4: Police Tactics, 1974), se plantea de forma seria, por fin, el enfrentamiento activo entre las fuerzas policiales y la mafia. Pero esa confrontación no viene motivada por un cambio en las relaciones entre administración y yakuza, sino en otros aspectos. La sociedad japonesa, cada vez más estabilizada, ve con recelo las actividades de las organizaciones criminales, y esa visión es adoptada por la administración, con los Juegos Olímpicos de Tokio 1964 como telón de fondo. 
El país es puesto a prueba por la comunidad internacional, y por ello debe limpiar sus calles de delincuencia en la medida de lo posible. Al menos debe mostrar voluntad de hacerlo frente a sus ciudadanos.

La presencia policial en las tres anteriores entregas había sido testimonial. Alguna aparición breve, siempre corriendo por callejones tras los delincuentes, sin mostrar sus intervenciones, usando las elipsis de forma inteligente para evitar enseñar lo obvio. Sin embargo, en Police Tactics se hace necesario un mayor peso en el metraje por parte de las fuerzas policiales. Police Tactics marca, en fin, un cambio en la tendencia al alza de la expansión criminal, marca el final de una edad dorada del crimen organizado, y marca, a la postre, la transformación definitiva de la nación japonesa: con el crimen controlado, Japón terminaría de entrar, de nuevo, en la élite internacional -de la que probablemente nunca salió desde el final del siglo XIX.

Jingi naki tatakai: Kanketsu-hen (The Yakuza Papers, Vol. 5: Final Episode, 1974) plantea el conflicto surgido entre la legalizada mafia y los yakuza tradicionales. Ya en la década de los años 70, las familias mafiosas centran sus esfuerzos en escudarse en sindicatos y empresas legales para mantener al margen a la policía y a la opinión pública. Sin embargo, una facción de la mafia está en contra de esto y quiere imponer una vuelta al pasado. Esta facción interpreta que con la transformación los valores primarios se perderán. Es interesante observar cómo Fukasaku traslada a su yakuza los problemas que la sociedad japonesa afrontaba, dos décadas después de la posguerra. Por un lado, el temor a perder la identidad, y por otro, el deseo de abrirse enteramente a la modernidad, de abrirse al mundo. Pero en esta quinta película de la saga The Yakuza Papers, que cierra la historia, no hay respuestas. No hay soluciones.

La semilla de la violencia sembrada con las sucesivas guerras en las que participó Japón, y la desorientación de la posguerra condujeron a los sucesos que Kinji Fukasaku narra a lo largo de de sus cinco películas. Y son semillas que permanecen en la tierra durante generaciones. A veces, como malas hierbas, son imposibles de erradicar. Esa desesperanza es la que el realizador trata de transmitir con el fin de la saga. Hirono se retira, harto de ver morir a jóvenes en las inútiles luchas mafiosas. Y el narrador se encarga de dejar claro que la 
violencia continúa imparable, sin oposición posible, a pesar de la transformación producida en la yakuza en la década de los 70.

Hay dos elementos simbólicos que permanecen constantes a lo largo de todas las entrega de estas batallas sin honor ni humanidad. Uno es la insistencia en dar un final amargo a cada filme -tres de ellos acaban en funeral por muertes de inocentes-. El otro es ese edificio derruido a causa de los bombardeos (El Monumento de la Paz de Hiroshima), que continúa imperturbable y fantasmal al cierre de cada uno de los filmes que componen Batallas sin honor ni humanidad. Porque, a pesar de los años transcurridos narrativamente, el génesis de los hechos transcurridos sigue ahí, a la vista de todos, y la reconstrucción de una nación debe asegurarse sobre la base de su historia

\section{Conclusiones}

A lo largo de este texto se ha expuesto una visión sobre la representación que Kinji Fukasaku realizó del Japón de posguerra. Esta visión dista mucho de ser totalizadora, puesto que el objetivo principal del estudio era entender la historia japonesa de pre y posguerra utilizando la saga Battles Without Honor and Humanity como elemento transmisor.

Battles Without Honor and Humanity muestra la evolución de la sociedad japonesa a lo largo de cinco largometrajes. La sociedad que inicialmente está derrotada, reducida casi al salvajismo y la violencia como expresión común de desamparo, poco a poco va tomando aire, e inicia una ascensión económica de la mano de la yakuza. El crimen organizado es empleado también para mostrar las carencias y contradicciones de un sistema político aparentemente eficaz, pero corrupto como el mismo hampa. Y todo ello mientras la población japonesa se transforma, pasa de ser una sociedad sombría y controlada por extranjeros a ser un territorio próspero.

Uno de los aciertos de Kinji Fukasaku fue el de emplear a la yakuza para relatar dicha transformación de forma atractiva, crimen mediante. He ahí una muestra de la inteligencia del director, utilizando cine comercial de género por un lado, y mostrando a la vez ciertas derivas personales y autorales por otro, cambiando, 
de paso, el yakuza-eiga, llevándolo a un nuevo terreno, alargando su vida con importantes novedades.

Por tanto, tal y como se ha expuesto, Battles Without Honor and Humanity es el relato del renacimiento de la nación japonesa, con sus virtudes y defectos. Es, de hecho, el relato del renacimiento de cualquier nación. La saga se convierte, pues, en última instancia, en el paradigma de la evolución de una sociedad. Es el estudio mismo de dicha evolución, utilizando, como ya se ha dicho, el mundo del crimen organizado, con lo que eso conlleva.

\section{Referencias bibliográficas}

Aguilar, Daniel (2001). Nada está en su sitio: el mundo loco de Seijun. En Cueto \& Robles (eds.), El desierto bajo los cerezos en flor: el cine de Seijun Suzuki (pp. 3-8). Madrid: Áqaba.

Armao, Fabio (2003). Why is organized crime so successful? En Felia Allum \& Renate Siebert (Ed.), Organized Crime and the Challenge to Democracy, (p. 32). Nueva York: Routledge.

Aumont, J., \& Marie, M. (1988). Análisis del film. Barcelona: Paidós.

Bailey, Paul J. (1996). Postwar Japan. 1945 to the Present. Oxford: Blackwell Publishers.

Caldevilla, David (2009). Neorrealismo italiano. Frame: revista de cine de la Biblioteca de la Facultad de Comunicación, 4, 23-25.

Coox, Alvin D. (1988). Nomonhan: Japan Against Russia, 1939. Stanford: Stanford University Press.

Dubro, A., \& Kaplan, David E. (2007). Los honorables proscritos: origen y mito de la yakuza. En R. Cueto y J. Palacios (Eds.), Asia Noir: Serie negra al estilo oriental (pp. 51-67). Madrid: T\&B Editores.

Falck, Melba E. (2007). La experiencia de desarrollo del Japón en la posguerra. En Calva, J.L. (Coord.), Desarrollo económico: estrategias exitosas (pp. 171-200). México D.F.: Universidad Autónoma de México.

Fridell, Wilbur M. (1976). A Fresh Look at State Shinto. Journal of the American Academy of Religion, 44 (3), 547-561.

Fukase-Indegaard, F., \& Indegaard, M. (2008). Religious Nationalism and the Making of the Modern Japanese State. Theory and Society, 37 (4), 343374 .

Giménez Soria, Carlos (2008). El ángel ebrio y El perro rabioso. La situación social de la posguerra a través del cine de Akira Kurosawa. En http://dialnet.unirioja.es/servlet/autor?codigo=153111Tápiz Fernández, José 
María (coord.), La historia a través del cine: China y Japón en el siglo $X X$ (pp. 95-105). Bilbao: Universidad del País Vasco, Servicio de Publicaciones.

Gómez Tarín, F. C. (2010). El análisis de textos audiovisuales: significación y sentido. Santander: Shangrila Ediciones.

Guerrero Plaza, Raúl (2009). Los Burakumin en la prensa japonesa: El Asahi Shimbun como caso de estudio. Historia y comunicación social, 14, 221244.

Hah, Chong-do, \& Lapp, Christopher C. (1978). Japanese Politics of Equality in Transition: The Case of the Burakumin. Asian Survey, 18 (5), 487-504.

Havens, Thomas R.H. (1978). Valley of Darkness: The Japanese People and World War Two. New York: Norton.

Holmes, John Clellon (1997). La Generación Beat. León: Universidad de León.

Howell, David L. (1998). Territoriality and Collective Identity in Tokugawa Japan. Daedalus, 127 (3), 105-132.

Kurosawa, Akira. (2013). No lo comprendo, no lo comprendo. Almería: Confluencias.

Lagos Matus, G. (2011). Mac Arthur y la transición de Japón a la democracia. Estudios Internacionales, 30 (119-120), p. 255-274.

Maffi, Mario (1975). La cultura underground I. Barcelona: Anagrama.

Masafumi, Okazaki (2010). Chrysanthemum and Christianity: Education and Religion in Occupied Japan, 1945-1952. Pacific Historical Review, 79 (3), 393-417.

Niogret, H. (2011). Kinji Fukasaku: Un cinéaste critique dans le chaos du xx siècle [reseña]. Positif, 6oo, 66.

Phillips, Michael F. (2009). A Cinematic Challenge to Modernity Critical Theory in Postwar Japanese Cinema: An Introduction to Fukasaku Kinji. [Tesis de graduado]. Consultado (01-12- 2013) de: https://digital.library.txstate.edu/handle/10877/3162

Rodao, Florentino (1995). Japón y Asia 50 años después. Política Exterior, 9 (46), 68-82.

Rubin, Jay (1985). From Wholesomeness to Decadence: The Censorship of Literature under the Allied Occupation. Journal of Japanese Studies, 11 (1), 71-103.

Rubio, Daniel (2006). Desarrollo y Pérdida; diferencias culturales y sociales desde el Japón de preguerra hasta la actualidad. En P. San Ginés Aguilar (Ed.), La investigación sobre Asia Pacífico en España (pp. 247-265). Granada: Editorial Universidad de Granada.

Schilling, Mark (2007). Entrevista a Kinji Fukasaku. En R. Cueto y J. Palacios (Eda.), Asia Noir: Serie negra al estilo oriental (p. 154). Madrid: T\&B Editores. 
Shimahara, Nobuo (1984). Toward the Equality of a Japanese Minority: The Case of Burakumin. Comparative Education, 20 (3), 339-353.

Shimazono, Susumu (2005). State Shinto and the Religious Structure of Modern Japan. Journal of the American Academy of Religion, 73 (4), 1077-1098.

Shimazu, Naoko (2003). Popular Representations of the Past: The Case of Postwar Japan. Journal of Contemporary History, 38 (1), 101-116.

Smith, Emily (2013). The George Lucas Handbook - Everything you need to know about George Lucas. Brisbane: Emereo Publishing.

Tsujikawa, Aki (2007). Discursos hegemónicos, vida cotidiana e identidades en Japón 1955 - 1973. [Tesis de Maestría]. Consultado (27-11-2013) de: http://www.flacsoandes.org/dspace/handle/10469/1070\#.UsMDNCFQE $\mathrm{X} 4$

Winther, Jennifer A. (2008). Household Enumeration in National Discourse: Three Moments in Modern Japanese History. Social Science History, 32 (1), 19-46.

Yoshimi, Shunya (2005). Japanese Television: Early Development and Research. En Janet Wasko (Ed.), A Companion to Television (p. 546). Oxford: Blackwell Publishers. 